\title{
Review
}

\section{History of dose response}

\author{
William J. Waddell \\ Department of Pharmacology and Toxicology, School of Medicine, University of Louisville, Louisville, KY, USA
}

(Received October 19, 2009)

\begin{abstract}
An abbreviated history of the dose-response curve or chemical concentration-effect relationship is presented in this article. No attempt has been made to include all references on the subject. Just an outline, overview, and discussion of the most important eras are presented. The history of dose response may be divided roughly into three Eras, Preclassical, Classical, and Current. Paracelsus, who lived from 1493 to 1541 , must be recognized as the first one to realize that dose was the most important issue to deal with in determining whether a chemical was toxic or not. However, that issue seems to have been forgotten and is still ignored by some. The Classical Era began about 1900 and ended about the time of the death of Gaddum in 1965, during which almost all of the progress had been made in solving the parameters to use in analyzing data. The Current Era began with the acceptance of the linearized multistage model in the mid-1970's. In this author's opinion, the biggest mistake in all of toxicology occurred with the acceptance and use of the linearized multistage for DNA-reactive carcinogens with dose on a linear scale. It had been clearly established in the Classical Era that dose should be plotted on a logarithmic scale. Plotting dose on a linear scale distorts the curve for low doses so that any attempt to detect the relationship of dose of carcinogen to carcinogenesis is impossible.
\end{abstract}

Key words: Dose response, Log-linear plot, History

\section{INTRODUCTION}

The term "dose response" implies that a given dose produces a given response. Response in this article can be either of the two types of response. 1. An individual responding to graded doses with an increasing effect as the dose increases. 2. A population wherein each individual may show the effect while others do not; this may be referred to as a quantal response. The response or effect must be distinguishable from background or placebo. Unfortunately, much of the ancient literature deals with herbs or other naturally-occurring material and no attempt was made to separate the response from what might have occurred simply by chance. Consequently, the ancient literature is filled with mysticism, conjecture, and merely what would have occurred by chance alone.

This author has chosen to divide the history of dose response into three Eras, namely: Preclassical, Classical, and Current. This classification is, of course, arbitrary and it leaves Paracelsus as a lone figure in the preclassical era. That is pretty much as it should be because there are those that, even today, do not realize how everything is toxic if the dose is high enough, including water, sugar, and salt.
In addition, this article deals with whether dose should be plotted on a linear scale or a logarithmic scale; this is far more important than most realize.

\section{PRECLASSICAL ERA}

It should be stated that during the Preclassical Era dose was important, but only what dose was necessary to accomplish the desired effect, which might very well have occurred if the medication had not been given at all. In the case of mixtures, sometimes the relative amounts were stated, but nothing to indicate the relationship of dose to response. Paracelsus must be mentioned as apparently the first to realize that only the dose separates a poison from a drug.

\section{Biblical}

The Bible apparently does not say anything about dose; it assumes that any amount causes an effect. However, there is but casual mention of things that are poisonous or foods not to be eaten. The author of this manuscript has looked in Deuteronomy, Job, Romans, Psalms, James, Leviticus, and found no mention of dose and degree of

Correspondence: William J. Waddell (E-mail: bwaddell@louisville.edu) 
response, just poisons and foods not to be eaten (Holy Bible, 1971). These are the writings in the Bible where verses can be found on poisons, according to Borzelleca (2001); the author of the present article has not examined other chapters in the Bible.

\section{Egyptian}

The Ebers Papyrus (c. 1534 B.C.E.) and the George Smith Papyrus (c. 1550 B.C.E.) are the two most often cited medical documents of ancient Egypt. Other papyri dealing with medicine are the Kahun papyrus (c. 1825 B.C.E.) that deals mostly with gynecological matters. The Hearst papyrus, Chester Beatty papyrus, the Berlin papyrus, the London Medical papyrus, the Ramesseum papyri, Carlsberg papyrus, and the Brooklyn papyrus are others. The author of this manuscript has searched the Internet and other places for evidence of dose response in the Ebers papyrus, the George Smith papyrus, and the Kahun papyrus and found nothing to indicate that the ancient Egyptians appreciated that dose alone was important. One must, however, recognize that in ancient Egypt there was much superstition associated with illness. A physician, priest, and magician were often the same person in ancient Egypt. Many of the so-called medications were of no apparent value in treating the disease; hence whether the patient recovered from the illness was simply a matter of chance and had nothing to do with the administered material.

We do know that there were measuring vessels that were used during the $18^{\text {th }}$ dynasty. This is about the time period for the Ebers Papyrus; each vessel measured from $0.1 \mathrm{ml}$ to $6 \mathrm{ml}$ (Magdi Saba, M.D., personal communication). Apparently the measuring vessels were used only for relative portions of constituents (Fig. 1).

\section{Chinese}

Huang Ti, the Yellow Emperor, is said to have written "The Canon of Internal Medicine", but its true authorship is unknown. Shen-nung, (also known as Seng Nung), the Divine Plowman, tasted hundreds of plants and identified those helpful in curing certain diseases. These works on plants were recorded in the book, which may be transliterated as: "Seng Nung Ben Cao Chien" or in translation as "The Herbal Classic of the Divine Plowman." Seng Nung lived about 2800 B.C.E., but his book was recorded by an anonymous scribe in 101 B.C.E. (Huang, 1999).

China's first emperor, Huang Ti, ascended to the throne in 2696 B.C.E., about 100 years after Seng Nung; he and his cabinet members developed techniques to diagnose diseases and to use herbs in their treatment. However, nothing about dose response appears to have been said (Huang, 1999). It is said that one should first start with a dosage the size of a millet seed; if that portion does not cure the disease, the amount should be doubled; if the dis-

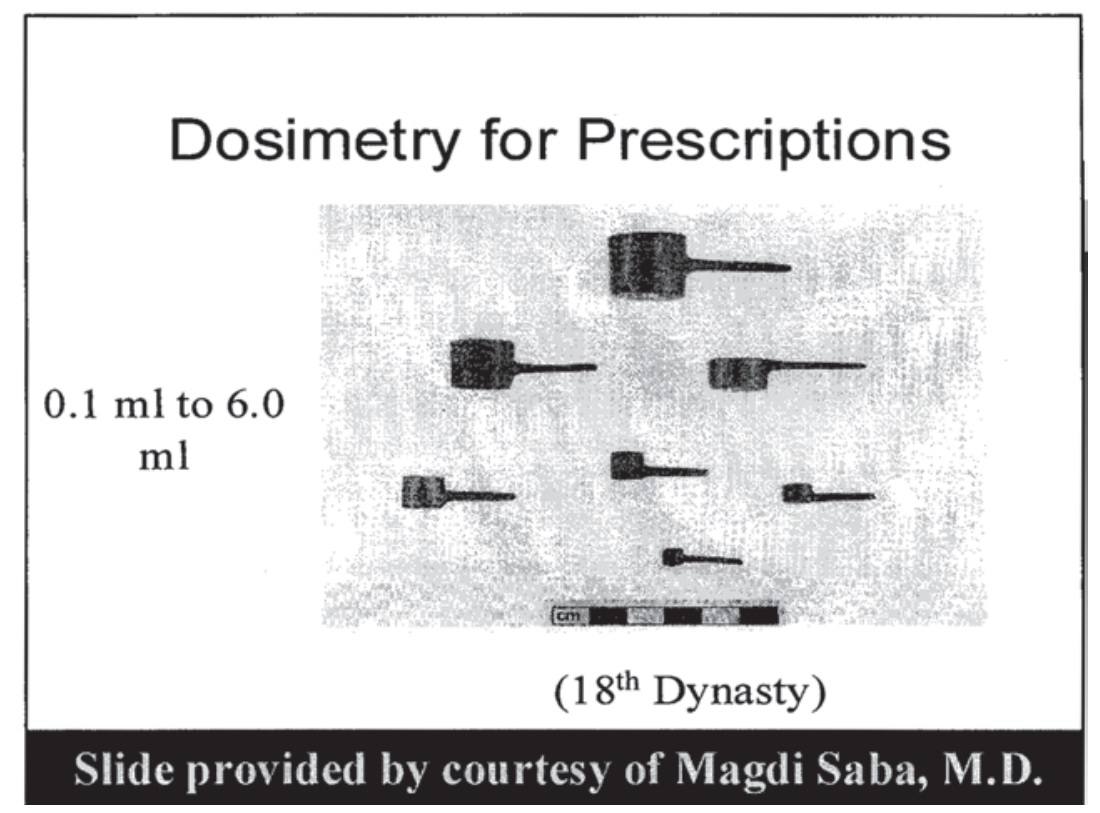

Fig. 1. Measuring vessels apparently for determining the relative amounts of materials in prescriptions. The Figure was provided by courtesy of Magdi Saba, M.D. 
History of dose response

ease persists the dose should be increased ten times. Cure of the disease should control the dose (Unschuld, 1986). Of course, the patient could have resolved the illness on his own or at least without the therapy, during this time interval.

One must understand that Chinese medicine is totally different from Western medicine; Chinese medicine is based on several classes of herbs. The upper class of drugs is known as "rulers" because they control the maintenance of life and correspond to heaven. It was recognized that this class of drugs does not have much medicinal power on its own and if taken over long periods of time causes no harm. The middle class of drugs is known as "ministers" that control the preservation of human nature and correspond to man. These are divided into two parts, one part delivers medicinal effectiveness and the other part does not. The lower class of drugs may be divided into "assistants" and "aides" because they control the curing of disease and correspond to earth (Unschuld, 1986).

It can be seen from the foregoing discussion of Chinese medicine that there is much superstition and mysticism involved and that it is quite different from Western medicine. There is no way to compare the two; therefore, it is difficult to discern anything about dose response.

Throughout the succeeding dynasties in China, there is no indication that anyone considered dose response. There is not much that can be said about current Chinese medicine; there is such a strong influence from traditional Chinese medicine, which depends on herbs and other naturally occurring substances. Apparently the current Chinese thinking is that Western medicine with its scientific basis is no better than traditional Chinese medicine (Huang, 1999).

\section{Hindu}

The Ayurveda is one of four Vedas (sacred writings); it was written about 700 B.C.E.; none of these works states any meaningful information about dose response. This author found Ayurveda medicine particularly lacking in science and filled with mysticism and superstition.

\section{Greek}

Pythagorus (582-507 B.C.E.), Hippocrates (460-369 B.C.E.), Aristotle (384-322 B.C.E.), King Mithridates VI (120-63 B.C.E.), Dioscorides (40-90 C.E.), Galen (130200 C.E.), and others are important figures in ancient Greek medicine. Hippocrates is best known for his introduction of the scientific method; sound observation and logical reasoning are the highlights. Aristotle is best known for his emphasis on nature as a science. Howev- er, all the Greek notables were hampered by their thinking that the body was composed of four humors: blood, phlegm, yellow bile, and black bile and that disease resulted from an imbalance of these. Four personality types characterized these: sanguine, phlegmatic, choleric, and melancholic. There is no indication that any of the Greek medical writers composed anything about dose response.

\section{Roman}

Aurelius Cornelius Celsus (30 B.C.E.-50 C.E.) was probably the most prominent medical writer of Rome. He wrote an encyclopedia dealing with agriculture, military art, rhetoric, philosophy, law, and medicine, of which only the medical portion (De medicina) has survived. De medicina was among the first medical works to be published after the introduction of the printing press (Encyclopedia Britannica, 1974). This author could find no reference to dose response in De medicina (Google, 2009).

\section{Arab}

Rhazes (865-932), Avicenna (980-1037), and Averroës (1126-1198) were three medical writers; Avicenna was the most well known. Avicenna published The Book of Healing and the Canon of Medicine among other writings. Contributions to pharmacy included sugar-coated pills and mixing drugs with rose water to render them better tasting (Borzelleca, 2001).

\section{Paracelsus}

A history of dose response would not be complete without a discussion of Paracelsus (1493-1541 C.E.). He is known as the father of toxicology because he was the first to publish an article pointing out that "what makes a man ill, also cures him"; i.e., the dose alone separates a toxic agent from a drug. He is quoted in the frontispiece of every edition of the famous toxicology textbook (Casarett and Doull) as saying "What is there that is not poison? All things are poison and nothing (is) without poison. Solely the dose determines that a thing is not a poison." He was born Philippus Aureolus Theophrastus Bombast von Hohenheim, but later took the name of Paracelsus because he regarded himself as even greater than Celsus, the great Roman medical writer (Encyclopedia Britannica, 1974). Logarithms were invented later by Napier in 1614, so Paracelsus apparently did not have a quantitative notion of how much difference there was between the dose of a substance that separated a poison from a drug. Low doses of a substance were useful as curative and relatively high doses of the same substance were considered toxic. 
An interesting quotation from Professor Henry Briggs is shown in Fig. 2 (Newman, 1956), which also shows when logarithms were invented. Other examples of the use of logarithms in society are: intensity of sound, which is measured in decibels; frequency of sound, which is synonymous with pitch in music; the Richter scale for earthquakes; chemical potential in thermodynamics, which applies to chemical reactions; and anywhere that percentages are used. Percentage is familiar to most people because of money lending; one usually does not figure interest as a fixed sum, regardless of the amount of the loan. One does not charge one dollar on either a million dollars or one dollar for a year; interest is most often figured as a percentage of the principle lent. This is exactly the same concept as logarithms.

\section{CLASSICAL ERA}

The Classical Era began about 1900 C.E. and ended about the time of the death of Gaddum in 1965. There is, of course, the homeopathic period before the classical era in which advocates of homeopathic medicine thought that the more dilute a medicine, the greater effect it had. The author of this article considers homeopathy so ridiculous that it does not deserve consideration in this review. This would mean that a single molecule present within the orbit of Uranus would have more effect on an individual than a much higher concentration.

Notable individuals in the classical era are John N. Langley (1852-1926), Paul Ehrlick (1854-1915),
Walter Straub (1874-1944), Irving Langmuir (18811957), Alfred J. Clark (1885-1941), A. V. Hill (18861977), John Gaddum (1900-1965) and H. O. Schild (1906-1984). It is probably worthwhile to quote from some of their writings to give an idea of the position they took on dose response.

Quotations from the book, when discussing the kinetics of drug actions on cells, by Clark (1933) will serve well to illustrate that the Classical Era scientists knew much about dose response, perhaps even more than many scientists do in the Current Era. "No drug produces an effect at infinite dilution, for the living cell possesses powers of resistance and repair, and hence there is always a certain threshold concentration necessary for the production of any given effect. All time-concentration curves will therefore start from a certain threshold concentration at which the effect measured is only produced after a delay so long that time may be regarded as equal to infinity."

Another quotation from that same book (Clark, 1933) states as follows. "Concentration-action curves in the case of many drugs, including hormones, follow approximately the relation that action varies as the logarithm of the concentration."

Gaddum (1959) gave an example as follows: "A warm day which adds a hundredth of a ton to a 5-ton elephant will not add the same weight to a 5-milligram maggot; it is more likely to add a hundredth of a milligram. The effect of each change on the weight of the animal is, in fact, likely to be proportional to the weight itself. Allowance can be made for this fact by calculating the weight

\section{Comment by Henry Briggs, Professor of Geometry in London, at his first meeting with John Napier, inventor of logarithms, in Edinburgh in 1615:}

"My Lord, I have undertaken this long journey purposely to see your person, and to know by what engine of wit or ingenuity you came first to think of this most excellent help unto Astronomy, viz. The Logarithms: but My Lord, being by you found out, I wonder nobody else found it out before, when now being known it appears so easy."

(Source: The World of Mathematics: James R. Newman; Simon and Schuster, New York, Vol.1, page 124, 1956)

Fig. 2. This Figure is self-explanatory. Its source is shown. 
History of dose response

of the animal in logarithms, since the difference between $\log 5$ tons and log 5.01 tons is the same as the difference between log $5 \mathrm{mg}$. and log $5.01 \mathrm{mg}$.; and this holds true whatever units of weight are used." (Bold added for emphasis.) It is, of course, obviously easy to extrapolate this example to doses of drugs.

Fig. 3 shows an example, from the book by Clark (1933), of how logarithmic dose applies to the relationship between vitamins and growth. The Figure has logarithms of the dose in milligrams on the abscissa and growth from either cod-liver oil or yeast extract as a linear scale on the ordinate.

\section{CURRENT ERA}

The Current Era begins approximately with the acceptance and use by the U. S. Environmental Protection Agency (USEPA) of the linearized multistage (LMS) model (Guess and Crump, 1976). A later assessment of the LMS model appeared (Crump, 1996). This era marked the beginning of the purely statistical approach to solving all events in toxicology at the expense of science. For some reason, this procedure, the LMS, has been applied only to DNA-reactive carcinogens; it has not been applied to

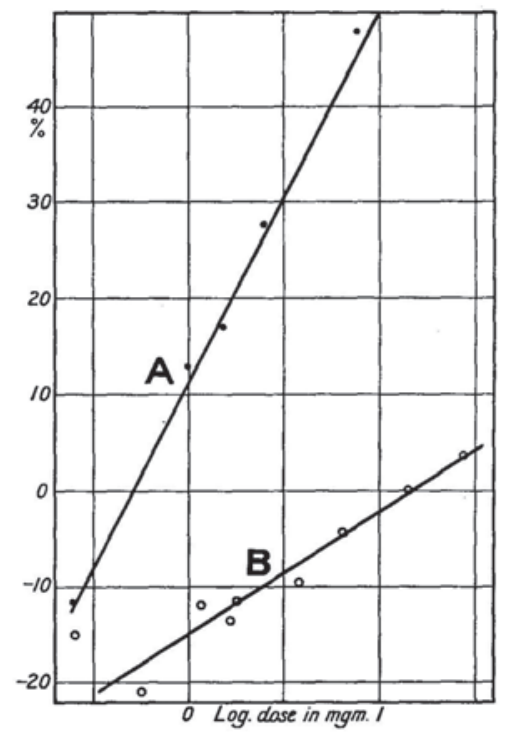

Fig. 54.-The relation between vitamin dosage and growth. ABscissa : logarithm of dose in mg. ORDINATE : the per cent. increase of the original body weight.

CURve A. Effect of cod-liver oil fed for five weeks to rats. (Coward, Kay et al. 1930.)

CURVE B. Effect of yeast extract fed for three weeks to pigeons. (Pilcher and Sollmann. 1926.)

Fig. 3. This Figure is from the book entitled "The Mode of Action of Drugs" by A. J. Clark. The Figure is reproduced unchanged. other dose-response curves in pharmacology and toxicology. One must simply compare linear scales with logarithmic scales for doses of carcinogens to determine the error with this approach. Examples for some DNA-reactive carcinogens are shown below.

Fig. 4 shows esophageal tumors from nitrosodiethylamine on rats at different doses. The experiment was conducted on a total of more than 4,000 rats in an attempt to discern the shape of the dose-response curve. Data are from Table 3 in the publication by Peto et al. (1991). The doses are plotted on a linear scale as those authors did; this is consistent with most of the thinking in the Current Era. Notice that the dose that humans get from eating one slice of bacon per day is indistinguishable from zero dose. Also, notice that the correlation coefficient is acceptably high, but that the data points are clearly curved convex upward (supralinear in Current Era nomenclature). It has been pointed out previously that the term 'supralinear' is meaningless unless the scales are defined (Waddell, 2006). When both scales are linear and the curve is convex upward (supralinear), the shape of that curve simply indicates that the abscissa should be logarithmic.

Fig. 5 shows exactly the same data plotted on the Rozman scale (Rozman et al., 1996). The Rozman scale has three notable features. It is logarithmic for dose on the abscissa, which agrees with the laws of nature; it is continuous to one molecule, which allows all doses to be put in perspective; and it is in molecules instead of weight, which allows for differences in molecular weight of substances. Please notice that the dose humans receive from eating one slice of bacon per day is clearly seen and very different from zero dose. Also notice that the data points are linear since the abscissa is logarithmic, which conforms to the laws of chemistry (Waddell, 2008). Also, the correlation coefficient is better than that shown in Fig. 4. Furthermore, a clear threshold for tumor formation can be appreciated, which is certainly a larger dose than humans get from eating one slice of bacon per day.

Fig. 6 is another example; it shows the percentage of rats with hepatocellular carcinomas after oral treatment with methyl eugenol. The data are from the National Toxicology Program (NTP, TR491); the data are plotted on a linear scale for dose as is consistent with most of the thinking in the Current Era. Notice how the doses to which humans are exposed appear to be indistinguishable from zero. Also notice that the data points are supralinear, which is reflected in the logarithmic fit being almost perfect and better than the linear fit. However, as with nitrosodiethylamine, the correlation coefficient is acceptable and has deceived many into thinking that dose on a linear scale is proper. 


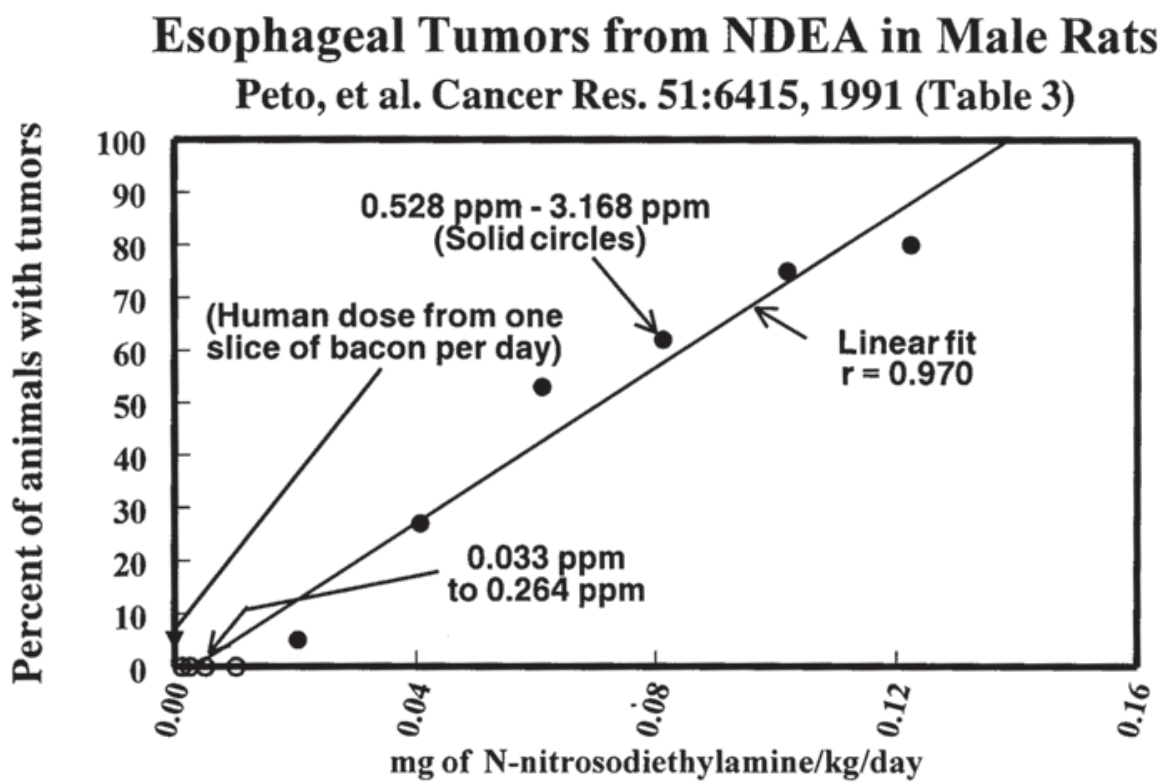

Fig. 4. Esophageal tumors from the administration of nitrosodiethylamine in male rats. The data are from the source shown. About 4,000 rats were used in this experiment to determine the shape of the dose-response curve. The data are plotted on a linear scale, as those authors did, and consistent with the thinking of many in the Current Era.

\section{Esophageal Tumors from NDEA in Male Rats}

Peto, et al. Cancer Res. 51:6415, 1991 (Table 3)

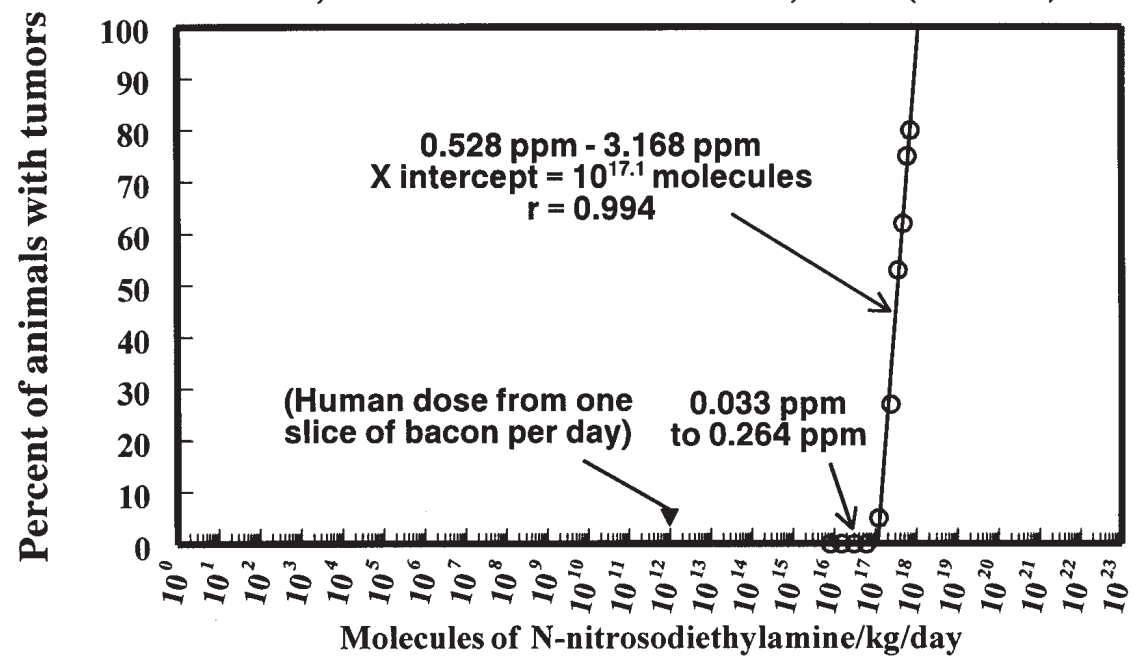

Fig. 5. The very same data as shown in Fig. 4, but plotted on the Rozman scale (Rozman et al., 1996). See text for discussion.

Fig. 7 shows what happens when the very same data, shown in Fig. 6, are plotted on the Rozman scale, which is logarithmic for dose and linear for effect. Notice that the doses to which humans are exposed are clearly distinguishable from zero and that a threshold for carcinogenicity is seen. Also, all doses are very far from one molecule/ $\mathrm{kg} / \mathrm{day}$, which is the smallest dose that can be given.

\section{SUMMARY AND CONCLUSIONS}

The Preclassical Era is so filled with mysticism, superstition, and misunderstanding that nothing can be said 


\section{F344/N Male Rats with Hepatocellular Carcinomas After Treatment with Methyl Eugenol (NTP Data)}

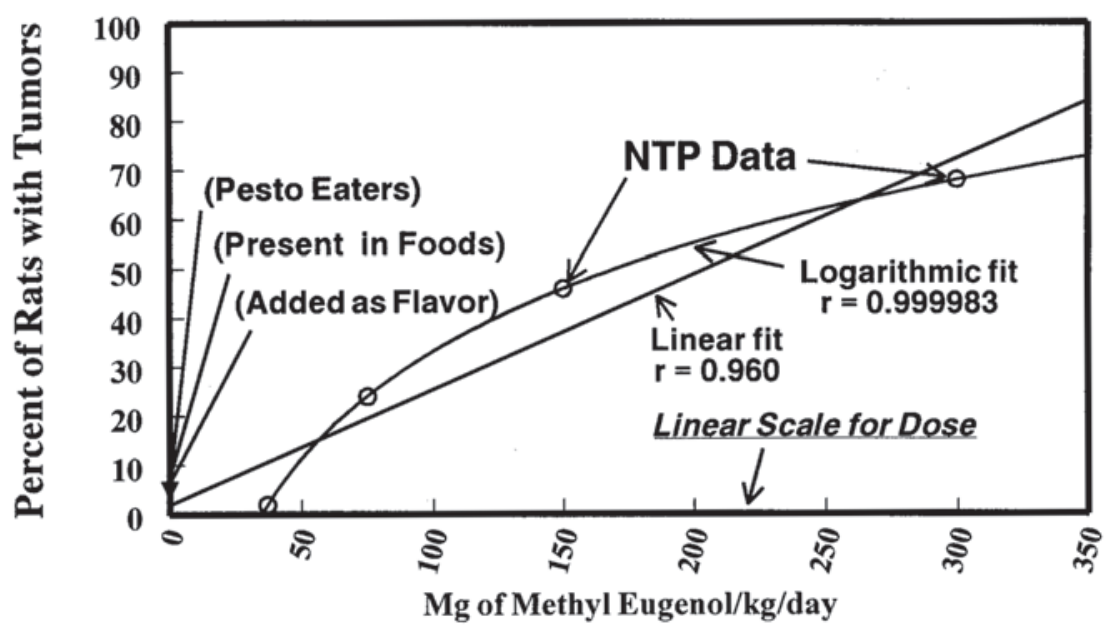

Fig. 6. Hepatocellular carcinomas in male rats after oral treatment with methyl eugenol. The data are from Technical Report 491 of the National Toxicology Program (available online). The data are plotted on a linear scale, which is consistent with thinking in the Current Era. Note that the doses humans receive appear to be zero.

\section{F344/N Male Rats with Hepatocellular Carcinomas After Treatment with Methyl Eugenol (NTP Data)}

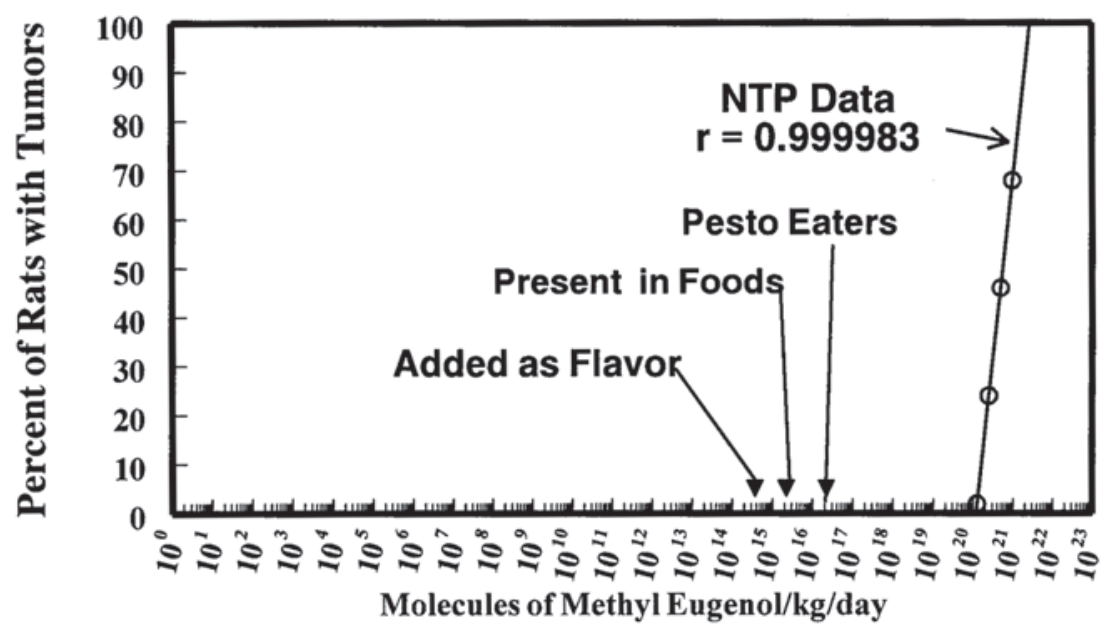

Fig. 7. The very same data as that shown in Fig. 6, but now plotted on the Rozman scale (Rozman et al., 1996). See text for discussion.

about dose response. Only Paracelsus, in the Preclassical Era, apparently appreciated that dose was important in determining toxicity.

The Classical Era, which began about 1900, was when most advances in dose response were made. Scientists in this Era used more of a scientific approach than those in the Current Era. Those in the Current Era rely more on statistical models.

The logarithmic scale for dose and linear scale for response is more than merely empirical; it is consistent with the laws of chemistry.

The linear scale for dose compresses low doses so 
severely that they cannot be evaluated. Human exposures may appear to be zero.

The Rozman scale for dose is ideal for all events in toxicology. It is logarithmic for dose, linear for effect, continuous to one molecule, and is in molecules instead of weight. Thresholds for tumor formation are clearly seen on this scale. The Rozman scale should be used for all adverse responses, in addition to tumor formation, because it conforms to the laws of nature.

\section{REFERENCES}

Borzelleca, J.F. (2001): The Art, the Science, and the Seduction of Toxicology: An Evolutionary Development. In: Principles and Methods of Toxicology (Hayes, A.W.,ed.), Fourth edition; Taylor and Francis, Philadephia.

Clark, A.J. (1933): The Mode of Action of Drugs on Cells. The William \& Wilkins Company, Baltimore.

Crump, K.S. (1996): The linearized multistage model and the future of quantitative risk assessment. Hum. Exp. Toxicol. 15, 787798.

Encyclopedia Britannica (1974): 15 ${ }^{\text {th }}$ Edition, Helen Hemingway Benton, Publisher.

Gaddum, J.H. (1959): Pharmacology, $5^{\text {th }}$ Edition, Oxford University Press, London.

Google; Internet. The author of this review article has searched many sites. 2008-2009.

Guess, H. and Crump, K. (1976): Low-dose extrapolation of data from animal carcinogenesis experiments. Math. Biosci. 32, 1536.

Holy Bible (1971): King James version, Thomas Nelson Publishers.

Huang, K. C. (1999): The Pharmacology of Chinese Herbs, Second edition; CRC Press, Boca Raton.

NTP TR 491 (2000): Toxicology and carcinogenesis studies of methyleugenol in $\mathrm{F} 344 / \mathrm{N}$ rats and $\mathrm{B} 6 \mathrm{C} 3 \mathrm{~F}_{1}$ mice. National Toxicology Program TR 491. Nashville Available online at http://ntpserver.niehs.nih.gov/.

Newman, J.R. (1956): The World of Mathematics, Volume 1, pp.124, Simon and Schuster, New York.

Peto, R., Gray, R., Brantom, P. and Grasso, P. (1991): Effects on 4080 rats of chronic ingestion of N-nitrosodiethylamine or Nnitrosodimethylamine: A detailed dose-response study. Cancer Res., 51, 6415-6451.

Rozman, K.K., Kerecsen, L., Viluksela, M.K., Österle, D., Deml, E., Viluksela, M., Stahl, B.U., Greim, H. and Doull, J. (1996): A Toxicologist's View of Cancer Risk Assessment. Drug Metab. Rev., 28, 29-52.

Unschuld, P.U. (1986): Medicine in China: A History of Pharmaceutics. University of California Press, Berkeley.

Waddell, W.J. (2006): Critique of dose response in carcinogenesis. Human and Experimental Toxicology, 25, 413-436.

Waddell, W.J. (2008): Thermodynamic basis for expressing dose logarithmically. Toxicol. Appl. Pharmacol., 228, 156-157. 